Editorial

\title{
Editorial for the Special Issue “Modern Raman Spectroscopy of Minerals"
}

\author{
Thomas Schmid 1,2,*(D) and Petra Dariz ${ }^{2,3}$ \\ 1 Bundesanstalt für Materialforschung und-prüfung, Richard-Willstätter-Str. 11, 12489 Berlin, Germany \\ 2 School of Analytical Sciences Adlershof (SALSA), Humboldt-Universität zu Berlin, Unter den Linden 6, \\ 10099 Berlin, Germany; petra@petradariz.eu \\ 3 Bern University of Applied Sciences, Bern University of the Arts, Conservation-Restoration, Fellerstr. 11, \\ 3027 Bern, Switzerland \\ * Correspondence: thomas@schmid.eu.com or thomas.schmid@bam.de
}

Received: 22 September 2020; Accepted: 27 September 2020; Published: 29 September 2020

check for updates

\section{Introduction}

Raman spectroscopy provides vibrational fingerprints of chemical compounds, enabling their unambiguous identification. The assignment of Raman spectra to minerals is straightforward, if appropriate reference data are accessible. Modern couplings of Raman spectroscopy with microscopy (Raman microspectroscopy) merge the high structural specificity with down to sub-micrometre spatial resolution. In addition to the chemical identity of minerals, Raman spectra are affected by crystal orientations (varying relative Raman band intensities); (sub)stoichiometric compositional changes (e.g., in solid solution series), traces of foreign ions, and strain (the latter three shifting Raman bands); and crystallinity (changing Raman band widths), enabling a comprehensive physico-chemical characterisation of minerals (see Figure 1a) [1]. Thus, Raman spectroscopy-including its in situ measurement capabilities-provides possibilities to study mineral paragenesis in natural samples and in both ancient and modern man-made materials at the micrometre scale.

(a)
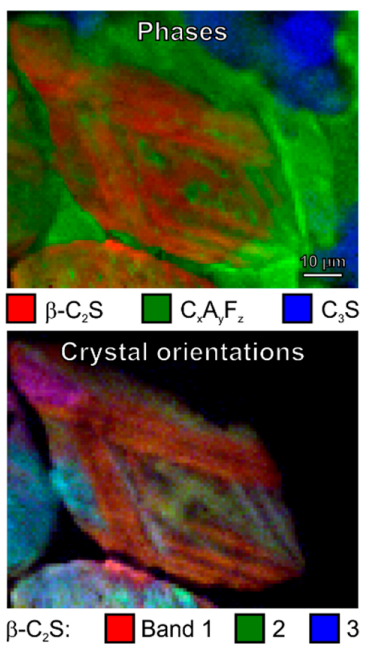
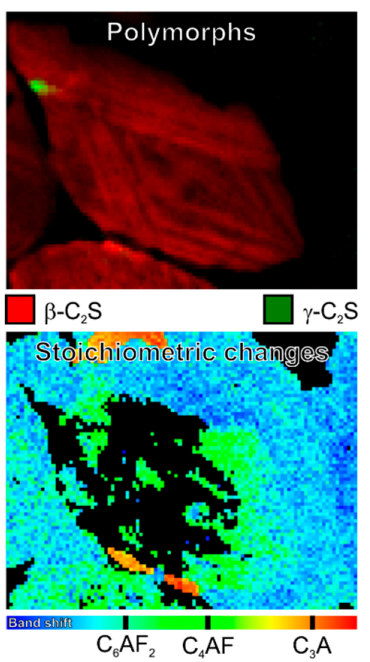

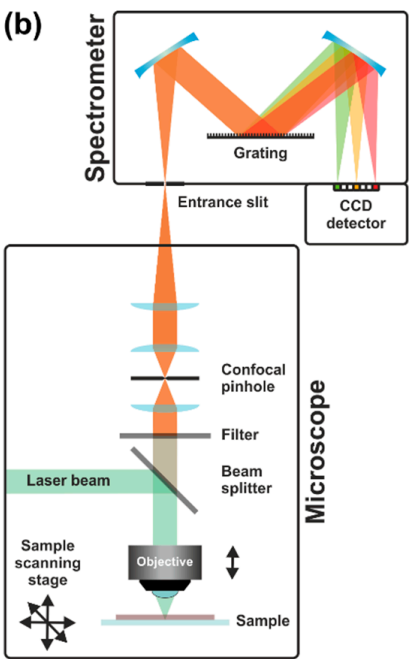

Figure 1. (a) Summary of chemical and physical properties of minerals that can be derived from Raman spectra using a 19th century cement mortar as an example. (b) Schematic of a Raman microscope with a dispersive spectrograph (figures are adapted from [1]; see reference for details). CCD, charge coupled device. 
Whereas in 1928, the first experimental evidence for inelastic light scattering was provided by C. V. Raman and K. S. Krishnan using sunlight for excitation, filters for selecting the inelastically scattered light, and their eyes for detection (later, photographic plates for acquisition of spectra were employed) [2], modern Raman spectrometers make use of laser excitation, dispersive spectrographs, and charge coupled device (CCD) detection (see Figure 1b) [3]. This Special Issue includes technological developments and applications in the field of modern Raman spectroscopy of minerals in a broad sense, from natural mineral deposits and archaeological objects to inorganic phases in man-made materials. The studied minerals include fossil resins [4], typical rock-forming minerals (calcite, quartz, forsterite) [5], iron-sulphur species (e.g., mackinawite) [6], a range of sulphates (gypsum, bassanite, anhydrite III, anhydrite II [7]; celestine, barite [8]; ternesite [9]), as well as silicate minerals like garnets (e.g., almandine) [10].

\section{Technical Developments}

At least in parts of six out of seven studies published in this Special Issue, Raman micro-spectroscopy instruments according to the principle shown in Figure 1b were used [5-10]. Although only N. Böhme et al. made use of the full imaging capabilities of such instruments [9], some groups employed Raman microscopes for performing in situ measurements in heating stages developed for microscopic observation [7-9], and others needed the spatial resolution for specifically choosing spots for single-point measurements within complex samples [6], including positioning in three-dimensional space for identifying mineral inclusions [10]. These possibilities demonstrate why microspectroscopy instruments have become relatively widespread in research laboratories specialising in Raman spectroscopy. In the seventh study, B. Naglik et al. compared the performances of portable and benchtop Raman spectrometers. Miniaturised dispersive spectrometers typically come with trade-offs in sensitivity and spectral resolution, but their performance can be sufficient for many applications, including the identification of minerals, as successfully demonstrated for the example of fossil resins (see Figure 2) [4]. As more portable devices have become commercially available during the last years, applications of Raman spectroscopy in field studies of geology, archaeology, and related areas are expected to grow. Here, we would like to mention the first Raman device expected to land on the surface of Mars as part of NASA's Perseverance rover in 2021 [11], followed by the European ExoMars mission [12]. In both cases, Raman spectroscopy will be used to study minerals and search for potential organic molecules.

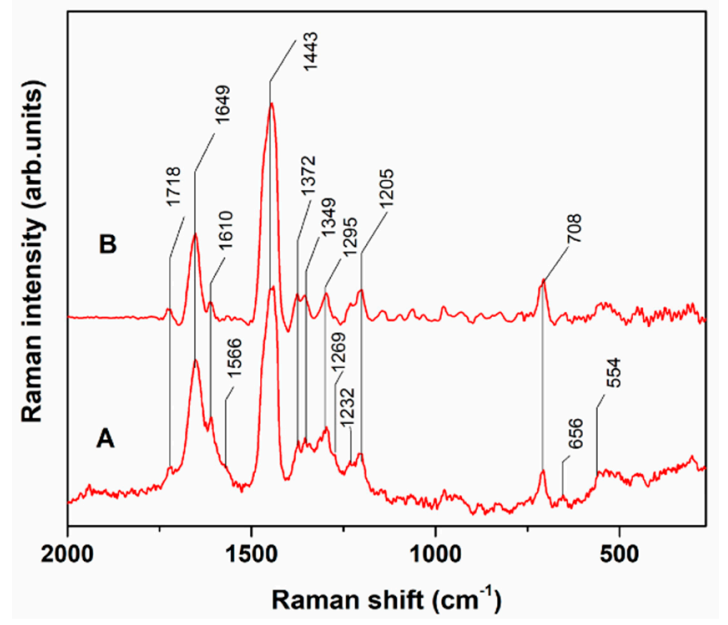

Figure 2. Examples of Raman spectra of a fossil resin (from Sakhalin, Russia) collected with (A) laboratory and (B) handheld equipment (figure from [4]; see reference for details).

In the context of making Raman spectrometers compact and mobile, the contribution by $\mathrm{A}$. Zettner et al. is of special interest, as it demonstrates the potential of spatial heterodyne Raman 
spectroscopy in the identification of minerals in rock samples and provides a comprehensive theoretical introduction as well as the pros and cons of this interferometric/Fourier transform (FT) spectrometer type (see Figure 3). Advantages over conventional dispersive spectrographs include high light throughput and high spectral resolution even in compact and thus potentially mobile instruments. A. Zettner et al. pre-characterised three rock samples with a research-grade Raman microscope and compared spatial heterodyne spectroscopy (SHS) measurements with data obtained at the exact same sample spots by employing a commercial dispersive handheld Raman instrument. SHS outperformed the dispersive portable device and reached approximately the same spectral resolution as the benchtop Raman microscope when using $300 \mathrm{~mm}^{-1}$ diffraction gratings in both configurations [5]. The potential of SHS for mobile Raman spectroscopy was recently underlined by the presentation of a monolithic device of about $35 \mathrm{~mm}$ linear dimension and less than $100 \mathrm{~g}$ weight by the group of S. M. Angel et al. [13].

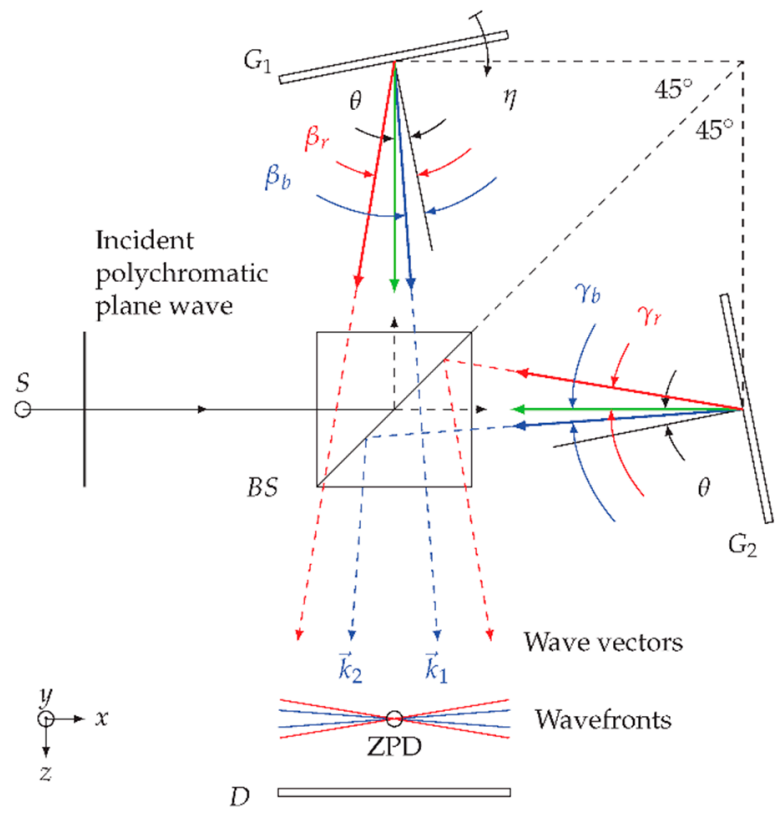

Figure 3. Basic principle of spatial heterodyne spectroscopy (SHS). $G_{1}$ and $G_{2}$ are fixed and tilted diffraction gratings replacing the mirrors of a Michelson interferometer (figure from [5]; see reference for details). ZPD, zero-path-difference line along axis $y$.

The studies by L. Zhou et al. [8], T. Schmid et al. [7], and N. Böhme et al. [9] make use of the in situ measurement capabilities of Raman spectroscopy by employing heating stages developed for microscopic observation. While all three studies derive characteristics of thermal expansion or phase conversions from single-spot temperature- and/or time-resolved measurements of minerals, N. Böhme et al. additionally realised in situ Raman microspectroscopic imaging by fast mapping during sample heating [9]. The same group introduced this approach in 2018 [14], successfully demonstrating its great potential for studies of solid-state reactions, polymorphic phase transformations, or recrystallisation processes at grain boundaries, and provided a detailed description of the technical workflow and applications to sintering processes in [15]. Applications of in situ Raman spectroscopy and imaging are detailed in Sections 4 and 5 below.

\section{Mineral Identification}

As mentioned above, Raman spectroscopy enables the unambiguous identification of minerals based on spectral patterns, which are sometimes termed spectroscopic fingerprints because of their specificity for a mineral type, its polymorphic form, and chemical composition [1]. Indeed, correct assignment of the Raman spectrum of an unknown sample is only feasible if the fingerprints of the potential suspects are known. Here, Raman spectroscopic database libraries come into play. 
Given the large number of Raman-active inorganic phases and organic molecules, such libraries can never be complete and are often restricted to a certain class of materials. In the field of mineral research, the most comprehensive and best known freely available collection of Raman spectra (in many examples combined with X-ray diffractograms and infrared spectra) can be found on the website of the RRUFF project (http://rruff.info) [16]. The database contains a few thousands of minerals, can be used to search for mineral names as well as chemical compositions, and the spectra can be viewed and rescaled on the website as well as downloaded in an ASCII text format. The latter feature is very valuable as it enables direct matching with own data. Further, less comprehensive spectra collections also offering this option are the Handbook of Raman Spectra for Geology hosted at École Normale Supérieure de Lyon (http://www.geologie-lyon.fr/Raman/)_also including a search option for wavenumbers - and the Raman Open Database (ROD) initiated within a European collaboration (https://solsa.crystallography.net/rod/), cross-linking Raman with crystallographic data [17]. An interesting addition is the collection of Selected Raman Spectra of Minerals provided by Institut für Mineralogie und Kristallographie at the University of Vienna, owing to the grouping of minerals into, for example, oxides, sulphates, and carbonates, although unfortunately, spectra can only be downloaded in PDF format (https://www.univie.ac.at/Mineralogie/Raman_spectra_engl.htm).

When, because of the complexity of a mineral class or because of shifted bands as a consequence of intermediate chemical compositions in solid solution series, the matching with database spectra reaches its limits, literature data are often the basis for mineral identification. Here, we would like to draw the reader's attention to a little collection of publications beyond this Special Issue, which we can recommend for the interpretation of the Raman data of some groups of minerals. Silicates are the most widespread and complex group of minerals found in the Earth's crust and mantle. In an extensive article, A. Wang et al. provide a valuable introduction into the Raman spectra of silicates and describe spectral features enabling their classification according to their degree of polymerisation [18]. The article focusses on phyllosilicates, which are sub-divided according to their layer sequences and Raman spectra, and in the case of the biotite series, between the end members phlogopite $\left(\mathrm{KMg}_{3}\left[\mathrm{AlSi}_{3} \mathrm{O}_{10}\right](\mathrm{OH})_{2}\right)$ and annite $\left(\mathrm{KFe}_{3}\left[\mathrm{AlSi}_{3} \mathrm{O}_{10}\right](\mathrm{OH})_{2}\right)$, an example for the correlation between Raman band wavenumbers and chemical compositions is given. Further knowledge on the broad field of silicates is added by studies specialising in selected mineral groups. For example, the olivines forsterite $\left(\mathrm{Mg}_{2}\left[\mathrm{SiO}_{4}\right]\right)$ and fayalite $\left(\mathrm{Fe}_{2}\left[\mathrm{SiO}_{4}\right]\right)$ and the according solid solution series have been extensively studied. T. Mouri and M. Enami studied the correlation of the type of olivine or the magnesium content within the forsterite-fayalite series with the positions of the two most prominent Raman bands of these nesosilicates [19]. L. B. Breitenfeld et al. evaluated the latter by additionally using multivariate data analysis [20], and H. Ishibashi et al. quantitatively studied the effect of crystal orientations on the relative Raman band intensities of a forsterite-fayalite olivine [21]. As another group of nesosilicates, garnets in a study by D. Bersani et al. were shown to be classifiable according to their molar compositions and crystal lattice parameters by evaluating their Raman band shifts [22]. Moving on to tectosilicates, a pioneering study on the classification of feldspars was published by T. Mernagh in 1991 [23], a co-author of a contribution to this Special Issue [8]. A very comprehensive article including the spectra of a large number of feldspars, and correlations between Raman shifts and compositions of the solid solution series albite-orthoclase $\left(\mathrm{Na}\left[\mathrm{AlSi}_{3} \mathrm{O}_{8}\right]-\mathrm{K}\left[\mathrm{AlSi}_{3} \mathrm{O}_{8}\right]\right.$, alkali feldspars), and albite-anorthite $\left(\mathrm{Na}\left[\mathrm{AlSi}_{3} \mathrm{O}_{8}\right]-\mathrm{Ca}\left[\mathrm{Al}_{2} \mathrm{Si}_{2} \mathrm{O}_{8}\right]\right.$, plagioclase feldspars), as well as of ternary feldspars in both diagrams and tabulated data, was published by J. J. Freeman et al. [24]. A detailed study of compositionally induced band shifts in plagioclase was presented recently by D. Bersani et al. [25], and K. S. Befus et al. investigated the pressure dependence of these bands as potential magmatic thermobarometers [26]. Silicates play an important role in cement chemistry, and our recommended read as an introduction to the Raman spectroscopy of cementitious materials is the comprehensive review article by L. Black from 2009 [27]. In this context, we also would like to mention our study on the phases of the lime cycle, which includes reference spectra of a characteristic luminescence emission 
observed in the Raman-inactive burnt lime $\mathrm{CaO}$ and of the Raman scattering of portlandite $\left(\mathrm{Ca}(\mathrm{OH})_{2}\right.$, slaked lime) and calcite $\left(\mathrm{CaCO}_{3}\right)$ [28].

The present Special Issue adds some more reference spectra to this collection. The article by Schmid et al. contains a comprehensive comparison of the Raman spectra and band positions of the four phases of the $\mathrm{CaSO}_{4}-\mathrm{H}_{2} \mathrm{O}$ system stable at room temperature: gypsum $\left(\mathrm{CaSO}_{4} \cdot 2 \mathrm{H}_{2} \mathrm{O}\right)$, bassanite $\left(\mathrm{CaSO}_{4} \cdot \frac{1}{2} \mathrm{H}_{2} \mathrm{O}\right)$, anhydrite $\mathrm{III}\left(\gamma-\mathrm{CaSO}_{4}\right)$, and anhydrite II $\left(\beta-\mathrm{CaSO}_{4}\right)$ (see Figure $\left.4 \mathrm{a}\right)$ [7]. Especially in the cases of bassanite and anhydrite III, the presented spectra are the most complete examples found in the literature so far, which can be explained by difficulties in their measurements arising from auto-fluorescence emission and the instability of the latter with respect to its reaction with air humidity, whereas for comprehensive theoretical and practical investigations of the Raman spectra of gypsum and anhydrite II, we would like to draw the reader's attention also to the pioneering studies of B. J. Berenblut et al. from the early 1970s [29,30]. The article by S. Kos et al. provides interesting reference data for Raman studies of garnets [10]. Its introduction section is our recommended read for researchers interested in the different types of garnets [31,32] found in late-antique to early-medieval jewellery, and the results section provides Raman spectra of different compositional groups of almandine $\left(\mathrm{Fe}_{3} \mathrm{Al}_{2}\left[\mathrm{SiO}_{4}\right]_{3}\right)$ garnets (types I and II according to [31], see Figure $\left.4 \mathrm{~b}\right)$ and their inclusions. Furthermore, Raman spectra of minerals acquired at elevated temperatures can be useful reference data in high-temperature studies and are included in this Special Issue for anhydrite II $\left(\beta-\mathrm{CaSO}_{4}\right)$ [7], celestine $\left(\mathrm{SrSO}_{4}\right)$, and barite $\left(\mathrm{BaSO}_{4}\right)[8]$.
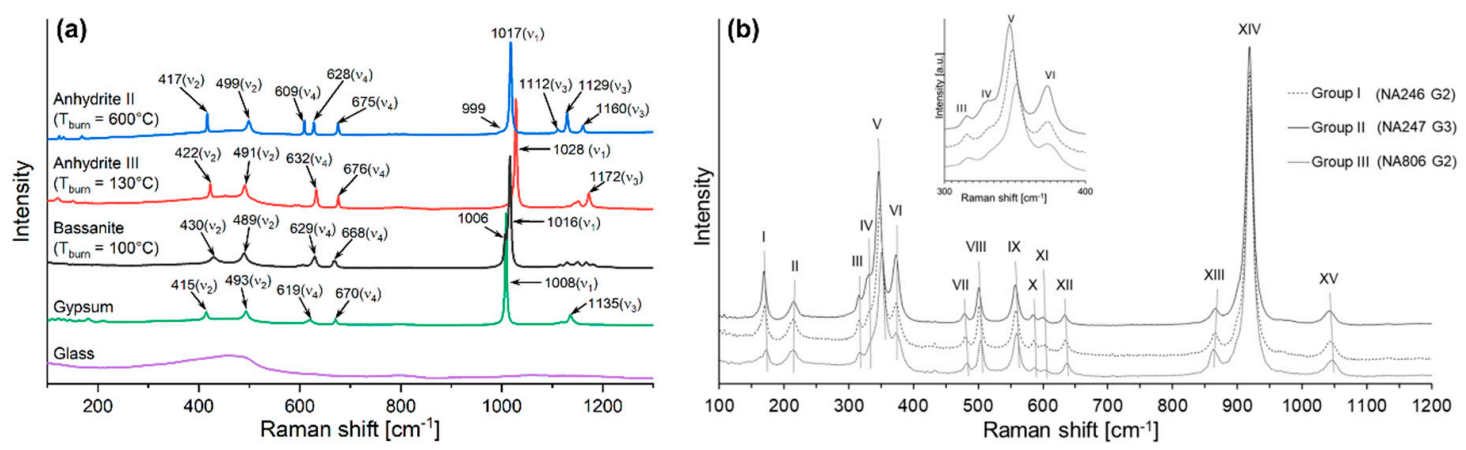

Figure 4. (a) Raman spectra of four phases of the $\mathrm{CaSO}_{4}-\mathrm{H}_{2} \mathrm{O}$ system, and (b) spectra of almandine garnets representative for three groups (figures adapted from [7,10]; see references for details).

\section{Basic Mineral Research}

Beyond the mineral type and chemical composition, Raman spectra can be affected by some of their physico-chemical properties. The present Special Issue includes two studies of physical properties further than the examples summarised by Figure 1a. L. Zhou et al. acquired the Raman spectra of celestine and barite in the temperature range of 25 to $600{ }^{\circ} \mathrm{C}$ (see Figure 5) and evaluated the changes of wavenumber positions and widths of their Raman bands, enabling the study of the anisotropic thermal expansion and the calculation of isobaric and isothermal mode Grüneisen parameters as well as anharmonicity parameters. The results suggest a lower thermal expansion along the $\mathrm{a}$ and $\mathrm{b}$ axes, and less sensitivity of $\mathrm{S}-\mathrm{O}$ and $\mathrm{S}-\mathrm{O}-\mathrm{S}$ distances and angles to pressure and temperature increase as compared with $\mathrm{M}-\mathrm{O}$ bonds (with $\mathrm{M}=\mathrm{Sr}$ or $\mathrm{Ba}$ ) [8].

The contribution by Schmid et al. extends these data towards calcium-another neighbour in the periodic table of elements—and presents temperature-dependent spectra of anhydrite II $\left(\beta-\mathrm{CaSO}_{4}\right.$, AII). With respect to AII, this study focusses on changes of physical properties depending on the calcination temperatures applied in its synthesis. After calcination of gypsum at burning temperatures increasing from 300 to $1100{ }^{\circ} \mathrm{C}$, the room-temperature Raman spectra of the resulting AII show a growing crystallinity revealed by narrowing of Raman bands and the healing of crystal lattice defects demonstrated by bleaching of auto-fluorescence. In accordance with tests of hydration reactivity, the results suggest replacement of the classical threefold sub-division of AII by the proposed sub-phases 
"disordered AII" and "crystalline AII". The Raman data reveal a transition temperature from reactive disordered AII to almost inert crystalline AII of $650{ }^{\circ} \mathrm{C} \pm 50 \mathrm{~K}$ [7].
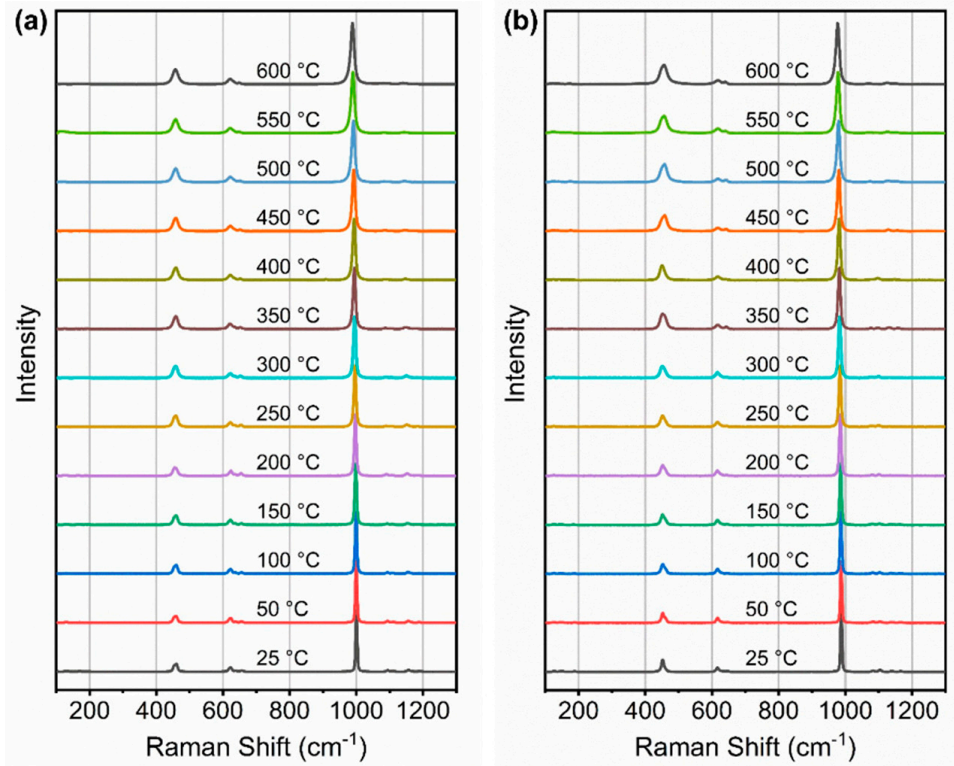

Figure 5. Raman spectra at atmospheric pressure of (a) celestine and (b) barite as functions of temperature (figures adapted from [8]; see reference for details).

\section{Applications}

The studies by B. Naglik et al. [4] and M. Monachon et al. [6] make use of the possibilities of Raman spectroscopy to study both inorganic phases and organic molecules. The Raman spectra of fossil resins consist of bands representing the typical vibrational modes of organic molecules, such as $\mathrm{C}-\mathrm{H}$ bending and $\mathrm{C}=\mathrm{C}$ stretching vibrations (see Figure 2). Fossil resins of various ages, botanical sources, geological environments, and provenances were characterised [4]. As resin maturation is typically accompanied by a loss of non-aromatic unsaturation during the aromatisation of penta- and hexacyclic rings in terpenoids, previous studies suggested the $v\left(C=C_{n o n-a r o m a t i c}\right) / \delta(C-H)$ intensity ratio as an age indicator [33]. B. Naglik et al. demonstrate that this does not hold true for all fossil resins, because geological conditions such as volcanic activity and/or hydrothermal heating might accelerate maturation processes [4].

M. Monachon et al. [6] used infrared and Raman spectroscopy to assess the efficiencies of different biological (Thiobacillus denitrificans and desferoxamine) and conventional chemical methods applied for extracting harmful $\mathrm{Fe} / \mathrm{S}$ species inducing degradation processes in archaeological waterlogged wood samples. Both vibrational spectroscopies are sensitive to organic and inorganic compounds and were used to trace potential damage to the wood as well as the presence and removal of $\mathrm{Fe} / \mathrm{S}$ species, such as elemental sulphur and partially oxidised mackinawite $\left(\mathrm{Fe}_{1-\mathrm{x}} \mathrm{S}\right)$. Reduced sulphur compounds were not identified anymore after biological treatment, whereas sulphur was still present for fresh and lake pine wood after chemical treatment (see Figure 6). Both treatments appeared to be quite smooth as no further wood degradation was observed [6]. In the same context of characterisation and conservation of historical objects and materials, the comprehensive study of garnets in late-antique jewellery from the Roman, Lombardic, and Ostrogothic archaeological site Lajh (Kranj, Slovenia) by S. Kos et al. [7] has to be mentioned. Raman spectroscopy of garnets and their inclusions indicated their assignment to type I and II garnets (almandine) [31] most likely originating from India, thus excluding other potential provenances, such as Sri Lanka, Bohemia, Portugal, or East Africa [10]. We would like to also mention the article on the $\mathrm{CaSO}_{4}-\mathrm{H}_{2} \mathrm{O}$ system in this context [7], because it is partially based on previous research on high-fired medieval gypsum mortars by the same team $[1,34,35]$. 


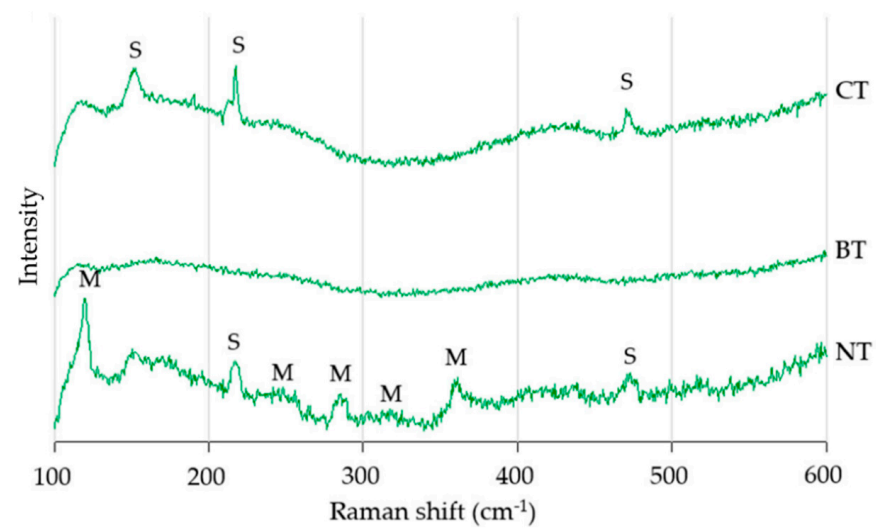

Figure 6. Raman spectra of untreated (NT) as well as chemically (CT) or biologically treated (BT) pinewood with characteristic bands of sulphur (S) and partially oxidised mackinawite (M) (figure adapted from [6]; see reference for details).

N. Boehme et al. [9] and T. Schmid et al. [7] applied in situ Raman spectroscopy to monitor mineral parageneses during calcination. T. Schmid et al. studied the reaction kinetics of gypsum-bassaniteanhydrite III conversions with a time resolution of $30 \mathrm{~s}$ at a constant temperature of $120{ }^{\circ} \mathrm{C}$, and found that reaction rates are strongly affected by water vapour transport, and thus-like in a physical drying process-depend on parameters further than the calcination temperature [7]. N. Böhme et al. studied the decomposition of ternesite $\left(\mathrm{Ca}_{5}\left[\mathrm{SiO}_{4}\right]_{2} \mathrm{SO}_{4}\right)$ into the high-temperature form of the cement clinker phase dicalcium silicate $\left(\alpha^{\prime} \mathrm{L}-\mathrm{Ca}_{2} \mathrm{SiO}_{4}\right)$, which, with a heating rate of $10{ }^{\circ} \mathrm{C} / \mathrm{h}$, happened between $730^{\circ} \mathrm{C}$ and $1120^{\circ} \mathrm{C}$. By in situ Raman microspectroscopic imaging, the authors were able to follow the solid-state reactions in the model system $\mathrm{CaO}-\mathrm{SiO}_{2}-\mathrm{CaSO}_{4}$ (see Figure 7). Both ternesite and $\alpha^{\prime} \mathrm{L}$-dicalcium silicate were found to co-exist at high temperatures, and crystallisation of either or both during quenching to room temperature depends on the reaction progress and possibly on the gas fugacity and composition in the furnace [9]. This study applies the recently developed experimental approach of in situ Raman microspectroscopic imaging [14,15] to a modern and industrially relevant mineral-related problem. Therefore, and because of the high scientific quality, it became the Editor's choice article of this Special Issue.

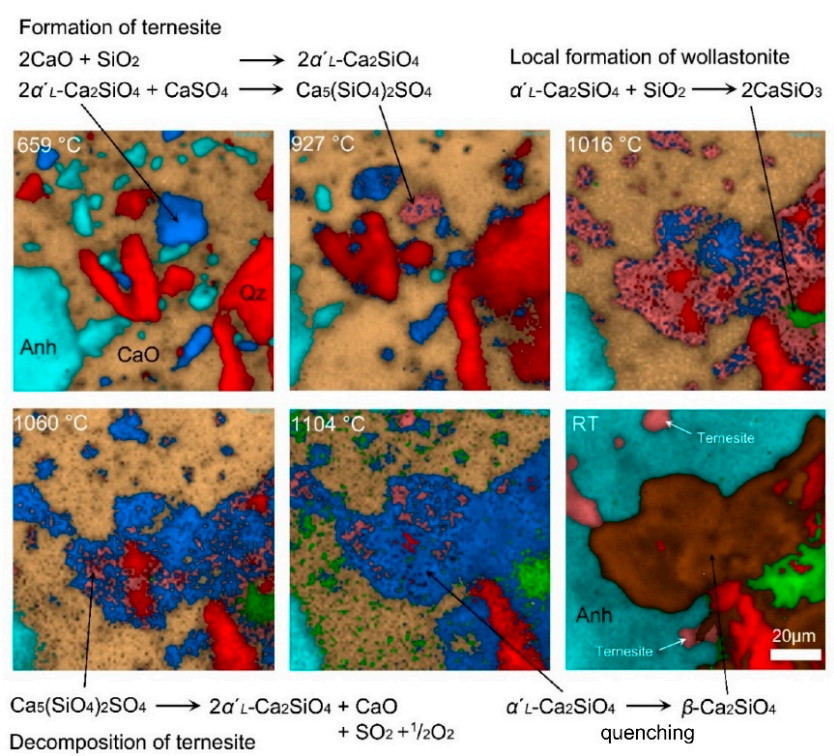

Figure 7. Selected reaction steps of $\mathrm{CaO}+\mathrm{SiO}_{2}+\mathrm{CaSO}_{4}$ observed by in situ Raman microspectroscopic imaging during heating and quenching (figure adapted from [9]; see reference for details). RT, room temperature. 
Acknowledgments: We thank all authors for their very valuable contributions of high scientific quality. We also greatly acknowledge MDPI-specifically Jinging Yang-for inviting us and for all the support as well as the open and helpful discussions during the elaboration of this Special Issue.

Conflicts of Interest: The authors declare no conflict of interest.

\section{References}

1. Schmid, T.; Dariz, P. Raman microspectroscopic imaging of binder remnants in historical mortars reveals processing conditions. Heritage 2019, 2, 102. [CrossRef]

2. Raman, C.V.; Krishnan, K.S. A new type of secondary radiation. Nature 1928, 121, 501-502. [CrossRef]

3. McCreery, R.L. Raman Spectroscopy for Chemical Analysis; John Wiley \& Sons: New York, NY, USA, 2000.

4. Naglik, B.; Mroczkowska-Szerszeń, M.; Dumańska-Słowik, M.; Natkaniec-Nowak, L.; Drzewicz, P.; Stach, P.; Żukowska, G. Fossil Resins-Constraints from Portable and Laboratory Near-infrared Raman Spectrometers. Minerals 2020, 10, 104. [CrossRef]

5. Zettner, A.; Gojani, A.B.; Schmid, T.; Gornushkin, I.B. Evaluation of a Spatial Heterodyne Spectrometer for Raman Spectroscopy of Minerals. Minerals 2020, 10, 202. [CrossRef]

6. Monachon, M.; Albelda-Berenguer, M.; Lombardo, T.; Cornet, E.; Moll-Dau, F.; Schramm, J.; Schmidt-Ott, K.; Joseph, E. Evaluation of Bio-Based Extraction Methods by Spectroscopic Methods. Minerals 2020, 10, 203. [CrossRef]

7. Schmid, T.; Jungnickel, R.; Dariz, P. Insights into the $\mathrm{CaSO}_{4}-\mathrm{H}_{2} \mathrm{O}$ System: A Raman-Spectroscopic Study. Minerals 2020, 10, 115. [CrossRef]

8. Zhou, L.; Mernagh, T.P.; Mo, B.; Wang, L.; Zhang, S.; Wang, C. Raman Study of Barite and Celestine at Various Temperatures. Minerals 2020, 10, 260. [CrossRef]

9. Böhme, N.; Hauke, K.; Neuroth, M.; Geisler, T. In Situ Hyperspectral Raman Imaging of Ternesite Formation and Decomposition at High Temperatures. Minerals 2020, 10, 287. [CrossRef]

10. Kos, S.; Dolenec, M.; Lux, J.; Dolenec, S. Raman Microspectroscopy of Garnets from S-Fibulae from the Archaeological Site Lajh (Slovenia). Minerals 2020, 10, 325. [CrossRef]

11. Beegle, L.; Bhartia, R.; White, M.; DeFlores, L.; Abbey, W.; Wu, Y.; Cameron, B.; Moore, J.; Fries, M. SHERLOC: Scanning habitable environments with Raman \& luminescence for organics \& chemicals. In Proceedings of the 2015 IEEE Aerospace Conference, Big Sky, MT, USA, 7-14 March 2015; pp. 1-11.

12. Vago, J.L.; Westall, F.; Coates, A.J.; Jaumann, R.; Korablev, O.; Ciarletti, V.; Mitrofanov, I.; Josset, J.L.; De Sanctis, M.C.; Bibring, J.P.; et al. Habitability on early Mars and the search for biosignatures with the ExoMars Rover. Astrobiology 2017, 17, 471-510. [CrossRef]

13. Allen, A.; Waldron, A.; Colon, A.; Raimundo, I.; Sharma, S.K.; Carter, J.C.; Angel, S.M. Remote LIBS, Ramanand hyperspectral Raman imaging using a monolithic spatial heterodyne spectrometer. In Proceedings of the FACSS/SCIX International Conference, Palm Springs, CA, USA, 16 October 2019.

14. Stange, K.; Lenting, C.; Geisler, T. Insights into the evolution of carbonate-bearing kaolin during sintering revealed by in situ hyperspectral Raman imaging. J. Am. Ceram. Soc. 2018, 101, 897-910. [CrossRef]

15. Hauke, K.; Kehren, J.; Böhme, N.; Zimmer, S.; Geisler, T. In situ hyperspectral Raman imaging: A new method to investigate sintering processes of ceramic material at high temperature. Appl. Sci. 2019, 9, 1310. [CrossRef]

16. Lafuente, B.; Downs, R.T.; Yang, H.; Stone, N. The power of databases: The RRUFF project. In Highlights in Mineralogical Crystallography; Armbruster, T., Danisi, R.M., Eds.; W. De Gruyter: Berlin, Germany, 2015; pp. 1-30.

17. El Mendili, Y.; Vaitkus, A.; Merkys, A.; Gražulis, S.; Chateigner, D.; Mathevet, F.; Gascoin, S.; Petit, S.; Bardeau, J.-F.; Zanatta, M.; et al. Raman Open Database: First interconnected Raman-X-ray diffraction open-access resource for material identification. J. Appl. Crystallogr. 2019, 52, 618-625. [CrossRef] [PubMed]

18. Wang, A.; Freeman, J.J.; Jolliff, B.L. Understanding the Raman spectral features of phyllosilicates. J. Raman Spectrosc. 2015, 46, 829-845. [CrossRef]

19. Mouri, T.; Enami, M. Raman spectroscopic study of olivine group minerals. J. Miner. Petrol. Sci. 2008, 103, 100-104. [CrossRef] 
20. Breitenfeld, L.B.; Dyar, M.D.; Carey, C.J.; Tague, T.J., Jr.; Wang, P.; Mullen, T.; Parente, M. Predicting olivine composition using Raman spectroscopy through band shift and multivariate analyses. Am. Mineral. 2018, 103, 1827-1836. [CrossRef]

21. Ishibashi, H.; Arakawa, M.; Ohi, S.; Yamamoto, J.; Miyake, A.; Kagi, H. Relationship between Raman spectral pattern and crystallographic orientation of a rock-forming mineral: A case study of $\mathrm{Fo}_{89} \mathrm{Fa}_{11}$ olivine. J. Raman Spectrosc. 2008, 39, 1653-1659. [CrossRef]

22. Bersani, D.; Ando, S.; Vignola, P.; Moltifiori, G.; Marino, I.-G.; Lottici, P.P.; Diella, V. Micro-Raman spectroscopy as a routine tool for garnet analysis. Spectrochim. Acta A 2009, 73, 484-491. [CrossRef]

23. Mernagh, T.P. Use of the Laser Raman Microprobe for Discrimination Amongst Feldspar Minerals. J. Raman Spectrosc. 1991, 22, 453-457. [CrossRef]

24. Freeman, J.J.; Wang, A.; Kuebler, K.E.; Jolliff, B.L.; Haskin, L.A. Characterization of natural feldspars by Raman spectroscopy for future planetary exploration. Can. Mineral. 2008, 46, 1477-1500. [CrossRef]

25. Bersani, D.; Aliatis, I.; Tribaudino, M.; Mantovani, L.; Benisek, A.; Carpenter, M.A.; Gatta, G.D.; Lottici, P.P. Plagioclase composition by Raman spectroscopy. J. Raman Spectrosc. 2018, 49, 684-698. [CrossRef]

26. Befus, K.S.; Lin, J.-F.; Cisneros, M.; Fu, S. Feldspar Raman shift and application as a magmatic thermobarometer. Am. Mineral. 2018, 103, 600-609. [CrossRef]

27. Black, L. Raman spectroscopy of cementitious materials. Spectrosc. Prop. Inorg. Organomet. Compd. 2009, 40, 72-127.

28. Schmid, T.; Dariz, P. Shedding light onto the spectra of lime: Raman and luminescence bands of $\mathrm{CaO}$, $\mathrm{Ca}(\mathrm{OH})_{2}$ and $\mathrm{CaCO}_{3}$. J. Raman Spectrosc. 2015, 46, 141-146. [CrossRef]

29. Berenblut, B.J.; Dawson, P.; Wilkinson, G.R. The Raman spectrum of gypsum. Spectrochim. Acta A 1971, 276, 1849-1863. [CrossRef]

30. Berenblut, B.J.; Dawson, P.; Wilkinson, G.R. A comparison of the Raman spectra of anhydrite $\left(\mathrm{CaSO}_{4}\right)$ and gypsum $\left(\mathrm{CaSO}_{4} \cdot 2 \mathrm{H}_{2} \mathrm{O}\right)$. Spectrochim. Acta A 1973, 29, 29-36. [CrossRef]

31. Calligaro, T.; Colinart, S.; Poirot, J.-P.; Sudres, C. Combined external-beam PIXE and $\mu$-Raman characterisation of garnets used in Merovingian jewellery. Nucl. Instrum. Methods Phys. Res. B 2002, 189, 320-327. [CrossRef]

32. Gilg, H.A.; Gast, N.; Calligaro, T. Vom Karfunkelstein. In Karfunkelstein und Seide: Neue Schätze aus Bayerns Frühzeit; Wamser, L., Ed.; Friedrich Pustet Verlag: München, Germany, 2010; pp. 87-100.

33. Winkler, W.A.; Kirchner, E.C.; Asenbaum, A.; Musso, M. A Raman spectroscopic approach to the maturation process of fossil resins. J. Raman Spectrosc. 2001, 32, 59-63. [CrossRef]

34. Dariz, P.; Schmid, T. Phase composition and burning history of high-fired medieval gypsum mortars studied by Raman microspectroscopy. Mater. Charact. 2019, 151, 292-301. [CrossRef]

35. Schmid, T.; Jungnickel, R.; Dariz, P. Raman band widths of anhydrite II reveal the burning history of high-fired medieval gypsum mortars. J. Raman Spectrosc. 2019, 50, 1154-1168. [CrossRef] 